\title{
Task 4.9 - Value-Added Products from Syngas
}

\author{
Semi-Annual Report \\ July 1 - December 31, 1996
}

\author{
By
Edwin S. Olson \\ By
Edwin S. Olson \\ Ramesh K. Sharma
}

RECEIVED

Alli 141997

OSTI

Work Performed Under Contract No.: DE-FC21-93MC30097

For

U.S. Department of Energy

Office of Fossil Energy

Morgantown Energy Technology Center

P.O. Box 880

Morgantown, West Virginia 26507-0880

By

Energy and Environmental Research Center

University of North Dakota

P. O. Box 9018

Grand Forks, North Dakota 58202-9018

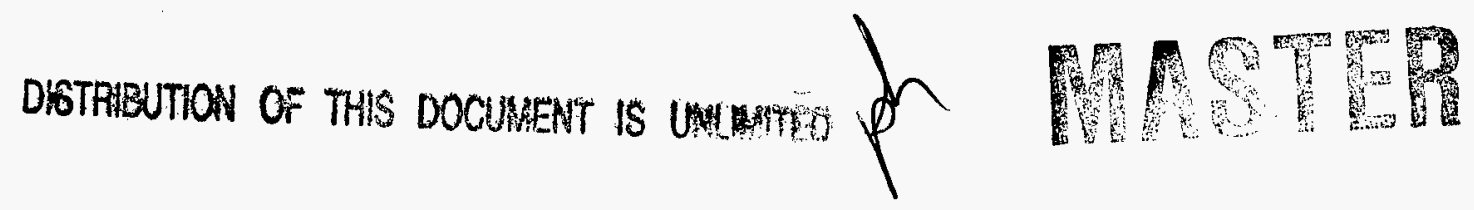




\section{Disclaimer}

This report was prepared as an account of work sponsored by an agency of the United States Government. Neither the United States Government nor any agency thereof, nor any of their employees, makes any warranty, express or implied, or assumes any legal liability or responsibility for the accuracy, completeness, or usefulness of any information, apparatus, product, or process disclosed, or represents that its use would not infringe privately owned rights. Reference herein to any specific commercial product, process, or service by trade name, trademark, manufacturer, or otherwise does not necessarily constitute or imply its endorsement, recommendation, or favoring by the United States Government or any agency thereof. The views and opinions of authors expressed herein do not necessarily state or reflect those of the United States Government or any agency thereof. 


\section{DISCLAIMER}

This report was prepared as an account of work sponsored by an agency of the United States Government. Neither the United States Government, nor any agency thereof, nor any of their employees makes any warranty, express or implied, or assumes any legal liability or responsibility for the accuracy, completeness, or usefulness of any information, apparatus, product, or process disclosed or represents that its use would not infringe privately owned rights. Reference herein to any specific commercial product, process, or service by trade name, trademark, manufacturer, or otherwise does not necessarily constitute or imply its endorsement, recommendation, or favoring by the United States Government or any agency thereof. The views and opinions of authors expressed herein do not necessarily state or reflect those of the United States Government or any agency thereof.

\section{ACKNOWLEDGMENT}

This report was prepared with the support of the U.S. Department of Energy (DOE), Federal Energy Technology Center, Cooperative Agreement No. DE-FC21-93MC30097. However, any opinions, findings, conclusions, or recommendations expressed herein are those of the author(s) and do not necessarily reflect the views of the DOE.

\section{EERC DISCLAIMER}

LEGAL NOTICE This research report was prepared by the Energy \& Environmental Research Center (EERC), an agency of the University of North Dakota, as an account of work sponsored by the U.S. Department of Energy. Because of the research nature of the work performed, neither the EERC nor any of its employees makes any warranty, express or implied, or assumes any legal liability or responsibility for the accuracy, completeness, or usefulness of any information, apparatus, product, or process disclosed, or represents that its use would not infringe privately owned rights. Reference herein to any specific commercial product, process, or service by trade, trademark, manufacturer, or otherwise does not necessarily constitute or imply its endorsement or recommendation by the EERC. 


\section{TABLE OF CONTENTS}

LIST OF FIGURES $\ldots \ldots \ldots \ldots \ldots \ldots \ldots \ldots \ldots \ldots \ldots \ldots \ldots \ldots \ldots \ldots \ldots$

EXECUTIVE SUMMARY $\ldots \ldots \ldots \ldots \ldots \ldots \ldots \ldots \ldots \ldots \ldots \ldots \ldots \ldots$ ii

INTRODUCTION $\ldots \ldots \ldots \ldots \ldots \ldots \ldots \ldots \ldots \ldots \ldots \ldots \ldots \ldots \ldots$

OBJECTIVES $\ldots \ldots \ldots \ldots \ldots \ldots \ldots \ldots \ldots \ldots \ldots \ldots \ldots \ldots \ldots \ldots \ldots \ldots \ldots$

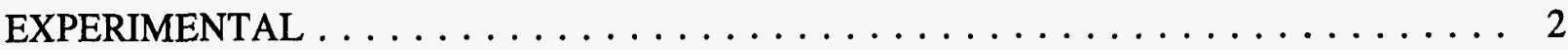

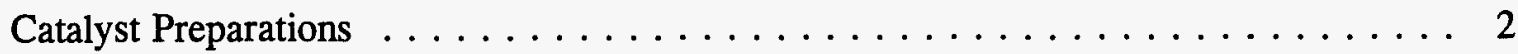

Catalytic Bed Reactions . . . . . . . . . . . . . . . . . . . 2

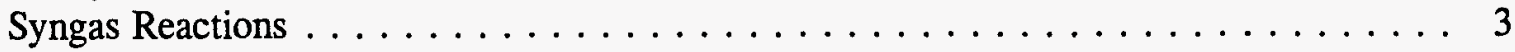

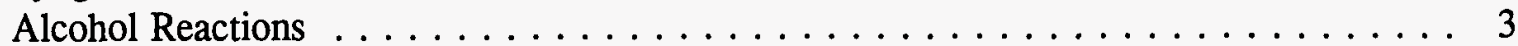

Batch Autoclave Reactions . . . . . . . . . . . . . . . . . 4

Analytical Procedures and Instrumentation $\ldots \ldots \ldots \ldots \ldots \ldots \ldots \ldots$

RESULTS AND DISCUSSION $\ldots \ldots \ldots \ldots \ldots \ldots \ldots \ldots \ldots \ldots$

Syngas Reactions . ....................... 4

Syngas Flow Reactor $\ldots \ldots \ldots \ldots \ldots \ldots \ldots \ldots \ldots \ldots \ldots \ldots$

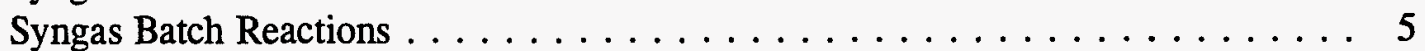

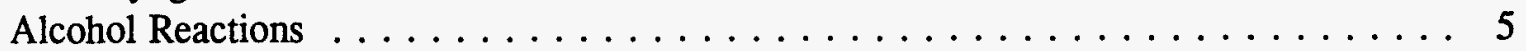

Alcohol Batch Reactions $\ldots \ldots \ldots \ldots \ldots \ldots \ldots \ldots \ldots \ldots$

Ethanol Bed Reactions $\ldots \ldots \ldots \ldots \ldots \ldots \ldots \ldots \ldots \ldots$

REFERENCES $\ldots \ldots \ldots \ldots \ldots \ldots \ldots \ldots \ldots \ldots \ldots \ldots \ldots$

\section{LIST OF FIGURES}

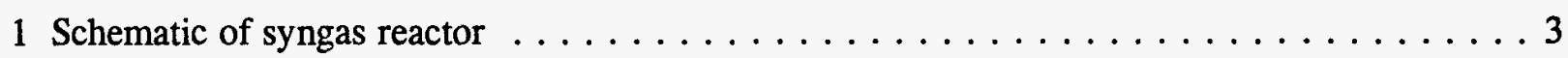




\section{TASK 4.9 VALUE-ADDED PRODUCTS FROM SYNGAS}

\section{EXECUTIVE SUMMARY}

The work on advanced fuel forms in 1996 focused on the synthesis of higher alcohols from mixtures of hydrogen and carbon dioxide (syngas) from coal gasification. This art has been practiced for many years in Germany, South Africa, and the United States. The conversion of coal gasification products to commercially valuable alcohols will provide an important new market for current and future gasification plants.

Initial work in this project utilized a novel molybdenum sulfide catalyst previously shown to be active for hydrodesulfurization reactions of coal liquids. The support for the active metal sulfide is a layered mixed oxide (hydrotalcite) capable of interaction with the metal sites for catalysis of carbon monoxide reductions. These catalysts have a high surface area, are highly porous, and have basic and acidic functionality. A pressurized fixed-bed flow-through reactor was constructed, and the $\mathrm{MoS}_{2}$ catalysts were tested with syngas under a variety of conditions. Unfortunately, the catalysts, even with higher molybdenum loading and addition of promoters, failed to give alcohol products. A batch reactor test of the catalyst was also conducted, but did not produce alcohol products.

Group VIII metals have been used previously in catalysts for syngas reactions. Ruthenium and rhodium catalysts were prepared by impregnation of a hydrotalcite support. Tests with these catalysts in flow-through reactors also did not produce the desired alcohol products.

The formation of higher alcohols from smaller ones, such as methanol and ethanol, could be commercially important if high selectivity could be achieved. The methanol and ethanol would be derived from syngas and fermentation, respectively. Based on previous work in other laboratories, it was hypothesized that the hydrotalcite-supported $\mathrm{MoS}_{2}$ or $\mathrm{Ru}$ or Rh catalysts could catalyze the formation of butyl alcohols. Although the desired 1-butanol was obtained in batch reactions with the promoted ruthenium catalyst, the reaction was not as selective as desired. Product suitable for a lower-vapor- pressure gasoline oxygenate additive was obtained, but it may not be economical to market such products in competition with methyl tertiary-butyl ether (MTBE). Flow-through catalytic bed reactions were not successful. 


\section{TASK 4.9 VALUE-ADDED PRODUCTS FROM SYNGAS}

\section{INTRODUCTION}

North Dakota has a large producer of synthesis gas (syngas) from coal (Great Plains Gasification Plant). Most of the syngas is converted to methane; however, the methane produced has been and will continue to be uncompetitive with natural gas. The conversion of syngas to chemicals or liquid fuel products (indirect liquefaction) has been extensively investigated in other laboratories for many years, but the commercialization of syngas conversions has only occurred a few times in this country. Currently, it does not make much sense to convert the syngas to a liquid fuel since this will be uncompetitive with petroleum for at least 10-20 years. It does make sense to convert syngas to chemical products which can compete with products currently produced from petroleum. The competitiveness is achieved by virtue of the selectiveness of the syngas reactions for a product or type of product.

A very large market already exists for many kinds of alcohols and their derivatives. Methanol is currently produced readily from syngas and, therefore, is relatively inexpensive. Alcohols with 3-6 carbons are produced from petroleum via pathways that involve several steps. They are used extensively in solvents, esters, and monomers. Consequently, the market prices of higher alcohols range from $\$ 0.50$ to $\$ 1.00 / \mathrm{lb}$; therefore, related compounds derived from alcohols, such as aldehydes, acids, and esters, are similarly priced. Dialcohols (diols) are worth even more (i.e., 1,4butanediol is currently $\$ 1.16 / 1 b$ ). Several catalysts have been used for higher alcohol synthesis from syngas, and Sasol produces alcohols in this way. Mixtures are generally obtained, and more efficient and selective catalysts are needed to improve the process. Larger alcohols can be synthesized from smaller ones. Methanol from syngas could be used in construction of branched alcohols. Some reactions may utilize locally produced grain ethanol as a feedstock for reaction with the syngas or with methanol.

Molybdenum sulfide has been investigated for syngas reactions that produce alcohol products (1-3). Alkali hydroxide is used with $\mathrm{MoS}_{2}$ to produce alcohols in the Dow process. Conversions are frequently low, and the major product is methanol; but the system is tolerant to $\mathrm{H}_{2} \mathrm{~S}$ (found in syngas from coal). The problem is how to increase the selectivity for larger alcohols. Another promising catalyst for alcohol synthesis is rhodium with suitable promoters.

\section{OBJECTIVES}

The objective of this task is to develop a process using existing Energy \& Environmental Research Center (EERC) layered catalysts (4) for conversion of syngas to higher alcohols. These catalysts contain very small active metal sites (nanoparticles), such as molybdenum sulfide clusters, embedded in the layers of the hydrotalcite support matrix. The mixed oxide layers of the hydrotalcite contain both basic and acidic sites. Acidic groups are also present to promote $\mathrm{C}-\mathrm{O}$ cleavage. By using the molybdenum sulfide in a bifunctional hydrotalcite matrix, the possibility exists for partially reduced intermediates to interact at the hydrotalcite sites and condense to larger species that will reduce to alcohol products. Thus the hydrotalcite matrix may increase the selectivity of the catalyst for alcohol products. 


\section{EXPERIMENTAL}

Bench-scale reactions of syngas at moderate temperatures and pressures were conducted to determine products and yields of alcohol products using the EERC molybdenum sulfide catalysts. As described above, the hydrotalcite-supported catalyst is unique since it contains a "nanogrid" of molybdenum sulfide sandwiched between a bimetallic oxide.

\section{Catalyst Preparations}

$\mathrm{MoS}_{2}-5-H T$ : A catalyst was prepared by exchanging ammonium tetrathiomolybdate (5 wt\%) into an aluminum magnesium oxalate hydrotalcite in an aqueous slurry. The exchanged hydrotalcite was heated to $400^{\circ} \mathrm{C}$ to decompose the oxalate and convert the tetrathiomolybdate to the molybdenum sulfide. The molybdenum content was $1.85 \%$.

$\mathrm{MoS}_{2}-35-\mathrm{Co} / \mathrm{K}-\mathrm{HT}$ : A second catalyst was prepared by exchanging $35 \mathrm{wt} \%$ ammonium tetrathiomolybdate into the hydrotalcite. The cobalt-potassium-promoted catalyst was then prepared by adding cobalt as the nitrate (5 wt $)$ to the dried molybdate-exchanged hydrotalcite and calcining and then adding potassium carbonate $(3 \mathrm{wt} \%)$ and drying. The molybdenum content was $13 \%$.

$R u / K-H T$ and $R h / K-H T$ : Hydrotalcite was added to a solution of ruthenium chloride trihydrate a small amount of water to make a paste. The paste was dried at $110^{\circ} \mathrm{C}$ followed by calcination at $400^{\circ} \mathrm{C}$ for 3 hours. The calcined product was added to an aqueous solution of anhydrous potassium carbonate to make a paste, which was similarly dried and calcined. Based on the reactant weights, the resulting catalyst has the following composition $\left(\mathrm{RuO}_{2}=0.25 \%\right.$, $\mathrm{K}_{2} \mathrm{O}=6 \%$, balance $\mathrm{HT}$ ). Another catalyst with $0.25 \% \mathrm{Rh}_{2} \mathrm{O}_{3}$ and $6 \% \mathrm{~K}_{2} \mathrm{O}$ on $\mathrm{HT}$ was prepared in a similar fashion.

Activation: The air-dried products were sized to separate +25 -mesh particles from the fines. For the activation of these catalysts, $5 \mathrm{~g}$ of the catalyst was packed in a stainless steel tube and activated in flowing hydrogen for 12 hours at $400^{\circ} \mathrm{C}$.

\section{Catalytic Bed Reactions}

Apparatus: An apparatus was constructed to conduct the syngas reactions over a fixed bed of the catalyst under pressurized flow conditions. The schematics of the apparatus are shown in Figure 1. A 6 in. tube reactor was packed with the desired catalyst $(+25 \mathrm{mesh})$ and attached to a syngas tank. The second end of the reactor was attached to two metal traps $(100 \mathrm{~mL})$. The first trap was cooled in ice, and the second was cooled in a dry ice-acetone slurry. The second metal trap was attached to a water displacement assembly via a needle valve for collecting the product gases. The reactor was placed in a vertical furnace.

In early reactions, the syngas was used without purification. In later runs, the $\mathrm{CO}_{2}$ in the syngas was removed by passing the gas through a column packed with ascharite. 


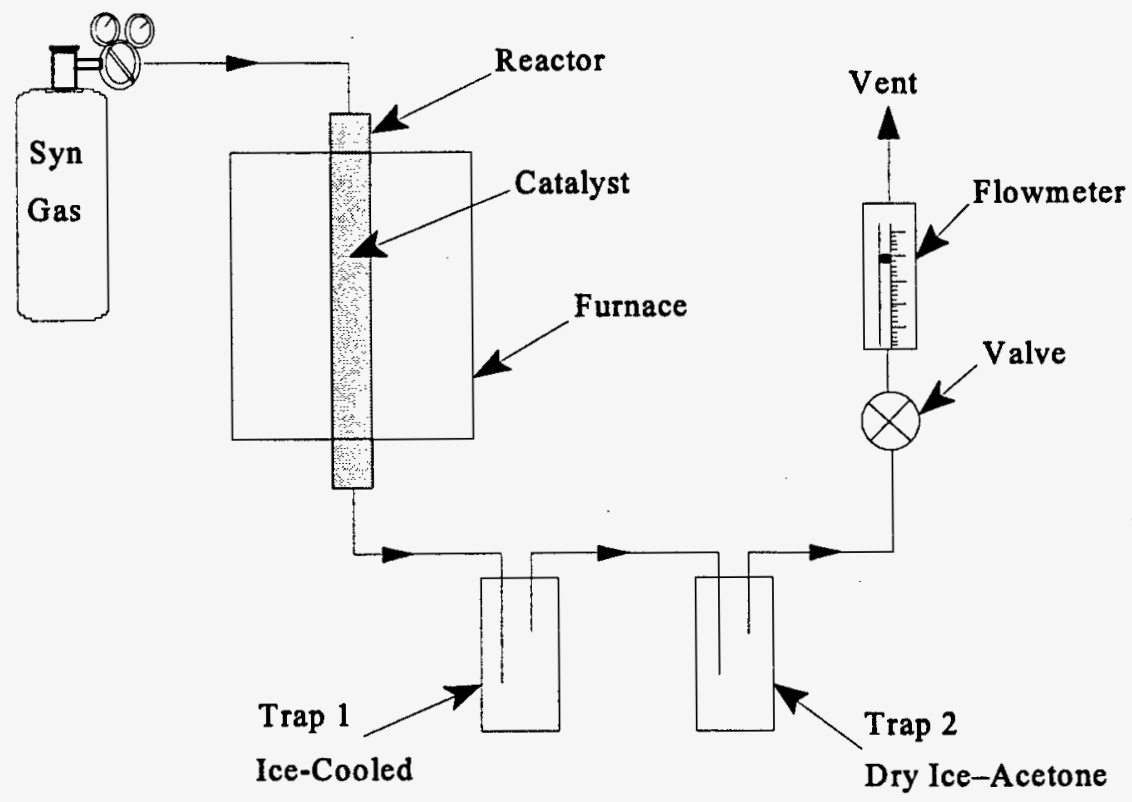

Figure 1. Schematic for syngas reactor.

\section{Syngas Reactions}

As described above, the catalyst was activated by heating in a flow of hydrogen $\left(8-10 \mathrm{~mL} / \mathrm{min}\right.$.) at $400^{\circ} \mathrm{C}$ for 12 hours. The reactor was heated to a desired temperature $\left(250^{\circ}-350^{\circ} \mathrm{C}\right)$ and then pressurized with $1000 \mathrm{psi}$ of syngas. The outflow of the gaseous product from the reactor was set at $100 \mathrm{cc} / \mathrm{min}$. After the desired reaction time, the flow of the gas was stopped, and the residual gas was allowed to bleed out from the system. The products from the traps were transferred into a $100-\mathrm{mL}$ volumetric flask by washing with methylene chloride, and the volume was made up to $100 \mathrm{~mL}$. A $10-\mathrm{mL}$ aliquot of the solution was mixed with $1 \mathrm{ml}$ of internal standard (2,2,4-trimethylpentane) in methylene chloride and analyzed by gas chromatography (GC).

\section{Alcohol Reactions}

The schematics of the apparatus are shown in Figure 1. A 6-in. tube reactor was packed with the desired catalyst $(+25 \mathrm{mesh})$ and was attached to a syringe pump. The second end of the reactor was attached to two metal traps $(100 \mathrm{~mL})$. The first trap was cooled in ice and the second in a dry ice-acetone slurry. The second metal trap was attached to a water displacement assembly via a needle valve for collecting the product gases. The reactor was placed in a vertical furnace. The catalyst was activated by heating in a flow of hydrogen $(8-10 \mathrm{~mL} / \mathrm{min})$ at $400^{\circ} \mathrm{C}$ for 12 hours. The reactor was heated to the desired temperature $\left(250^{\circ} \mathrm{C}\right)$ and then ethanol was passed through the heated catalyst at the rate of $15.2 \mathrm{~mL} / \mathrm{hr}$. After the desired reaction time, the flow of the ethanol was stopped, and the residual product was allowed to bleed out from the system. The products from the traps were transferred into a $100-\mathrm{mL}$ volumetric flask by washing with methylene chloride, and the volume was made up to $100 \mathrm{~mL}$. A $10-\mathrm{mL}$ aliquot of the solution was mixed with 
$1 \mathrm{~mL}$ of internal standard (2,2,4-trimethylpentane, in methylene chloride) and analyzed by GC. The gas was not collected, but in future runs it will be collected into a gas bag and analyzed by GC and FT-IR.

\section{Batch Autoclave Reactions}

All catalysts were activated by heating in a gentle flow of hydrogen at $400^{\circ} \mathrm{C}$ for 12 hours. In a typical experiment, $1 \mathrm{~g}$ of the desired catalyst and $2 \mathrm{~g}$ of ethanol (100\% or $95 \%)$ were placed in a $15-\mathrm{mL}$ microreactor. The reactor was evacuated, pressurized with $1000 \mathrm{psig}$ of $\mathrm{H}_{2}$, and placed in a rocking autoclave heated to the desired temperature. Heating was continued for 3 hours. At the end of the reaction period, the reactor was cooled to room temperature, degassed, and opened. The product slurry was extracted with methylene chloride, and the solid catalyst removed by centrifugation. The supernatant liquid was analyzed by GC.

\section{Analytical Procedures and Instrumentation}

Quantitative GC/flame ionization detection (FID) analyses were performed with a Hewlett Packard 5880. A gas chromatograph was equipped with a $100-\mathrm{m}$ petrocol capillary column. A mixture of 2,2,4-trimethylpentane and n-octadecane was the internal standard.

\section{RESULTS AND DISCUSSION}

\section{Syngas Reactions}

\section{Syngas Flow Reactor}

Reactions of syngas were carried out in a flow reactor under the following reaction conditions:

- Reaction temperature: $250^{\circ}, 300^{\circ}$, and $330^{\circ} \mathrm{C}$

- Syngas pressure: 400 and 1000 psi

- Reaction time: $1 \mathrm{hr}$

- Gas flow: $100 \mathrm{cc} / \mathrm{min}$

- Catalyst: $\mathrm{MoS}_{2}-5-\mathrm{HT}(1.85 \% \mathrm{Mo})$

The contents of the two traps were extracted with dichloromethane. An aliquot of the product was mixed with the standard and analyzed by GC. The chromatograms from all of these runs showed the absence of any volatile alcohol or hydrocarbon product or water. It is concluded that the catalyst used in these tests did not catalyze the conversion of syngas to higher alcohols. The catalyst had a low loading of molybdenum, and the molybdenum may have been imbedded too deeply in the oxide layers.

Reactions of syngas with the cobalt-potassium-promoted $\mathrm{MoS}_{2}-35$-HT catalyst were investigated. The much higher loading of $\mathrm{MoS}_{2}(13 \%)$ should provide a better activity, and the promotion effects of potassium and cobalt could be obtained. These reactions were performed in the flow-through reactor under the following conditions: 
- Reaction temperature: $250^{\circ}$ and $325^{\circ} \mathrm{C}$

- Syngas pressure: $1000 \mathrm{psi}$

- Reaction time: $1 \mathrm{hr}$

- Gas flow: $100 \mathrm{cc} / \mathrm{min}$

- Catalyst: $\mathrm{MoS}_{2}-35 / \mathrm{Co} / \mathrm{K}-\mathrm{HT}(13 \% \mathrm{Mo})$

Extraction of the two traps with dichloromethane and GC analysis indicated that no formation of higher alcohols occurred with this catalyst at the two temperatures investigated. A possible reason for the inactivity is that the addition of the potassium carbonate resulted in hydrolysis of the $\mathrm{MoS}_{2}$ to form molybdate. This reaction was avoided in the preparations of previous $\mathrm{MoS}_{2}-\mathrm{KOH}$ catalysts but might have occurred in this case. However, molybdate along with cobalt is known to catalyze the conversion of syngas to alcohols $(5,6)$. Thus the inactivity could be attributed to the nature of the hydrotalcite metal support for this type of reaction.

Reactions of $\mathrm{CO}_{2}$-free syngas with the hydrotalcite-supported rhodium catalyst $(\mathrm{Rh} / \mathrm{K}-\mathrm{HT})$ were performed at $300^{\circ} \mathrm{C}$. No alcohol products were observed. The ruthenium-impregnated catalyst $(\mathrm{Ru} / \mathrm{K}-\mathrm{HT})$ was also inactive.

\section{Syngas Batch Reactions}

The reaction of syngas with the $\mathrm{MoS}_{2}-35 / \mathrm{Co} / \mathrm{K}-\mathrm{HT}$ catalyst was then investigated in a batch reaction in a high-pressure autoclave. The reaction with $\mathrm{CO}_{2}$-free syngas was carried out in a $70-\mathrm{mL}$ autoclave with a shaker at $300^{\circ} \mathrm{C}$ for 3 hours under 1000 psi pressure. Five grams of pulverized catalyst was used. The $\mathrm{MoS}_{2}-35 / \mathrm{Co} / \mathrm{K}-\mathrm{HT}$ catalyst again gave no alcohol products. The reaction was then carried out with the similar silica-supported $\mathrm{MoS}_{2}-35 / \mathrm{Co} / \mathrm{K}$ catalyst utilized by Fujimoto (5). But again, no alcohol products were observed. Finally, the rhodium catalyst $(\mathrm{Rh} / \mathrm{K}-\mathrm{HT})$ was utilized, but no alcohols were produced.

\section{Alcohol Reactions}

Since difficulties in obtaining alcohol products from syngas were encountered, several hydrotalcite-supported catalysts were investigated for their activities for catalyzing Guerbet reactions of ethanol and methanol. If these Guerbet reactions are successful, technologies could be developed that will lead to increased utilization of both agricultural materials and coal-derived syngas by converting fermentation products to higher-value chemicals. Since ethanol can be produced for approximately $\$ 0.15 / \mathrm{lb}$ (fuel grade), it is a reasonably priced feedstock for synthetic chemistry. Methanol produced from syngas is much less expensive.

The Guerbet reaction (Equation 1) of ethanol by itself gives n-butyl alcohol (1-butanol) and other products, such as the further condensation of the 1-butanol product with a second ethanol molecule to give n-hexyl alcohol (Equation 2).

$$
\begin{array}{r}
\mathrm{CH}_{3}-\mathrm{CH}_{2}-\mathrm{OH}+\mathrm{CH}_{3}-\mathrm{CH}_{2}-\mathrm{OH} \rightarrow \mathrm{CH}_{3}-\mathrm{CH}_{2}-\mathrm{CH}_{2}-\mathrm{CH}_{2}-\mathrm{OH}+\mathrm{H}_{2} \mathrm{O} \\
\mathrm{CH}_{3}-\mathrm{CH}_{2}-\mathrm{CH}_{2}-\mathrm{CH}_{2}-\mathrm{OH}+\mathrm{CH}_{3}-\mathrm{CH}_{2}-\mathrm{OH} \rightarrow \mathrm{CH}_{3}-\mathrm{CH}_{2}-\mathrm{CH}_{2}-\mathrm{CH}_{2}-\mathrm{CH}_{2}-\mathrm{CH}_{2}-\mathrm{OH} \text { [Eq. 2] }
\end{array}
$$


The reaction is known to involve formation of an aldehyde intermediate by dehydrogenation of the alcohol. Two aldehyde molecules condense together (the aldol condensation) to give an unsaturated aldehyde, which is subsequently hydrogenated to the saturated alcohol product (Equation 3).

$$
\begin{aligned}
& 2 \mathrm{CH}_{3}-\mathrm{CH}_{2}-\mathrm{OH} \rightarrow 2 \mathrm{CH}_{3}-\mathrm{CH}=\mathrm{O} \rightarrow \mathrm{CH}_{3}-\mathrm{CH}=\mathrm{CH}-\mathrm{CH}=\mathrm{O}+\mathrm{H}_{2} \mathrm{O} \\
& \mathrm{CH}_{3}-\mathrm{CH}=\mathrm{CH}-\mathrm{CH}=\mathrm{O} \rightarrow \mathrm{CH}_{3}-\mathrm{CH}_{2}-\mathrm{CH}_{2}-\mathrm{CH}=\mathrm{O} \rightarrow \mathrm{CH}_{3}-\mathrm{CH}_{2}-\mathrm{CH}_{2}-\mathrm{CH}_{2}-\mathrm{OH}
\end{aligned}
$$

Branched alcohols of the secondary and tertiary type can also be produced in the Guerbet reaction if one uses a mixture of methanol and ethanol to give [1-propanol (Equation 4)]. The reaction involves formation of formaldehyde and acetaldehyde, which condense together and are then hydrogenated as described above. Further reaction with a second molecule of formaldehyde from methanol results in iso-butyl alcohol (Equation 5).

$$
\begin{aligned}
& \mathrm{CH}_{3}-\mathrm{CH}_{2}-\mathrm{OH}+\mathrm{CH}_{3}-\mathrm{OH} \rightarrow \mathrm{CH}_{3}-\mathrm{CH}_{2}-\mathrm{CH}_{2}-\mathrm{OH}+\mathrm{H}_{2} \mathrm{O} \\
& \mathrm{CH}_{3}-\mathrm{CH}_{2}-\mathrm{CH}_{2}-\mathrm{OH}+\mathrm{CH}_{3}-\mathrm{OH} \rightarrow\left(\mathrm{CH}_{3}\right)_{2}-\mathrm{CH}-\mathrm{CH}_{2}-\mathrm{OH}
\end{aligned}
$$

The condensation steps in the reaction require a basic catalyst. Sodium ethoxide or other alkali metal alcoholate $(7,8)$, phosphate $(9)$, or carbonate (10) were generally used for this purpose. These reactions required high temperatures and required that only one of the reactants contain a methylene group adjacent to the carbon containing the $\mathrm{OH}$ group. To aid in the dehydrogenation and hydrogenation steps in the reaction (Equation 3), nickel $(8,11)$, copper chromite $(10,12)$, platinum, palladium, ruthenium, or rhodium in a finely divided state (13), and organic zinc compounds (14), were used, and the reactions could be carried out at lower temperatures. The catalysts utilized in our syngas reactions can also be used in the Guerbet reactions, since they contain the basic function (mixed oxide) as well as the metal hydrogen-activating site ( $\mathrm{MoS}_{2}$ or other metal).

The catalyst systems are deactivated by the water by-product produced in the reaction (15). Primarily, previous reactions have been run in a batch mode, and a new base, such as sodium alkoxide, has been used in each batch. The water accumulating as a reaction product will obviously react with the alkoxide and produce hydroxide, which is less effective. The key to effecting economical condensation reactions of the Guerbet type is the use of a solid base catalyst bed in a continuous or flow-through reactor. In this mode, the water eliminated during the condensation does not accumulate in the reactor as it does in the batch reactor. Clark described a gas-phase reaction with a catalyst composed of a platinum group metal and alkali metal impregnated on alumina (16). Ueda recently reported (17) using a magnesium oxide catalyst for the gas-phase reaction of ethanol and methanol to give the mixture of propyl and t-butyl alcohols. Conversions of $60 \%$ (ethanol basis) were obtained at $390^{\circ} \mathrm{C}$ at atmospheric pressure, with a selectivity of $80 \%$ for alcohols. The catalytic activity decreased with time, however. Some unsaturated compounds including aldehydes were also produced, and methanol was partly converted to methane, $\mathrm{CO}$, and $\mathrm{H}_{2}$. 


\section{Alcohol Batch Reactions}

The Guerbet reaction was carried out with ethanol at $250^{\circ} \mathrm{C}$ in repeated runs with the $\mathrm{MoS}_{2}-\mathrm{HT}$ catalysts in a batch reactor for three hours in $500 \mathrm{psi} \mathrm{N}_{2}$. The $\mathrm{MoS}_{2}-\mathrm{HT}$ was activated by heating in tetralin at $400^{\circ} \mathrm{C}$ for three hours. The catalyst to substrate ratio was 0.1 . The major product was ethyl acetate along with smaller amounts of n-butanol and other unidentifiable products. The catalyst recovered from this run was reacted with fresh ethanol under the same conditions. Product distribution was same. The catalyst recovered from this reaction was reacted with anhydrous ethanol at $250^{\circ} \mathrm{C}$ in 500 psi of hydrogen for three hours. The product distribution was same as before. Thus the reaction does not seem to be affected by the water by-product; however, the major product (ethyl acetate) is not the desired one.

Previous work demonstrated that hydrotalcites catalyze condensation reactions of aldehydes (18). Thus, in this series of reactions, the side reaction of the aldehyde intermediate that forms the carboxylic acid (later esterified) is predominating over the condensation reaction. This implies that the hydrogen activation or transfer of hydrogen with concomitant electron transfer (oxidation) proceeds at a higher rate than base-catalyzed condensation. There does not seem to be the right balance of the two catalytic functions in this catalyst. Therefore, the cross reaction of methanol with ethanol was not investigated with the $\mathrm{MoS}_{2}$ catalyst.

Further exploratory reactions of ethanol were investigated with other hydrotalcite-supported catalysts. The highly porous Universal Fuel Development Associates (UFDA) hydrotalcite was converted to a different type of Guerbet catalyst by impregnating with rhodium and ruthenium rather than molybdenum. Anionic forms of these elements were exchanged onto the surface and potassium carbonate was added. The catalysts were activated in hydrogen at $400^{\circ} \mathrm{C}$ to convert the rhodium and ruthenium to their active metal forms.

A batch autoclave reaction of ethanol was carried by heating $2 \mathrm{~g}$ of $95 \%$ ethanol with $1 \mathrm{~g}$ of $\mathrm{Ru} / \mathrm{K} / \mathrm{HT}$ at $250^{\circ} \mathrm{C}$ for 3 hours in $1000 \mathrm{psi}$ of hydrogen (initial pressure). In this experiment, the major product was the desired product, 1-butanol (5 wt\%). A smaller amount of 2-butanol (1.3\%) also was formed. Other minor products were $\mathrm{n}$ - and branched chain hexanols and octanols resulting from further condensation reactions on the catalyst. These were not all characterized, however, and the products could have included aldehydes or esters (such as ethyl butyrate or butyl acetate) as well as alcohols. The catalyst recovered from this reaction was recycled, and the reaction of ethanol with the recovered catalyst gave a similar product distribution. The hydrotalcite-supported ruthenium catalyst gave the desired 1-butanol, but it was not a very clean reaction and would require more separation than desired. However, the mixture of products could be used as a gasoline oxygenate additive since the vapor pressure would be high with respect to ethanol. The catalyst was very stable; neither the support nor the metal were destroyed by the water produced in the reaction.

A hydrotalcite-supported rhodium catalyst was also investigated. The reaction of ethanol with $\mathrm{Rh} / \mathrm{K} / \mathrm{HT}$ under the above conditions gave only about $1 \% 1$-butanol and smaller amounts of higher alcohol products similar to the reaction described above. The lower activity of the rhodium catalyst is inexplicable. 


\section{Ethanol Bed Reactions}

The reaction of ethanol with the activated catalyst bed of $\mathrm{MoS}_{2}-\mathrm{HT} / \mathrm{Co} / \mathrm{K}$ was carried out in a flow reactor under the following reaction conditions:

- Reaction temperature: $250^{\circ} \mathrm{C}$

- Flow rate: $15.2 \mathrm{~mL} / \mathrm{hr}$

- Reaction time: $1 \mathrm{hr}$

The contents of the two traps were extracted with dichloromethane. An aliquot of the product was mixed with a standard and analyzed by GC. No alcohol products were produced in the reaction.

Reactions of ethanol with $\mathrm{RuO}_{2}-\mathrm{HT} / \mathrm{K}$ were carried out in a flow reactor under the following reaction conditions:

- Reaction temperature: $250^{\circ}-400^{\circ} \mathrm{C}$

- Flow rate: $15 \mathrm{~mL} / \mathrm{hr}$

- Reaction time: $1 \mathrm{hr}$

The reaction of ethanol in the reactor at $250^{\circ} \mathrm{C}$ gave a small amount of ethylene as the only product. Upon increasing the reaction temperature to $300^{\circ} \mathrm{C}$, the amount of ethylene increased somewhat. No other product was observed. However, when the reaction was carried out at $400^{\circ} \mathrm{C}$, the product consisted of a large number of components. The major product in the liquid phase was dissolved ethylene (10 wt\%). In addition to small amounts of n-butanol $(0.01 \%)$ and $\mathrm{n}$-hexanol $(0.04 \%)$, a large number of unidentified components totaling $6.75 \mathrm{wt} \%$ were also formed. It appears that condensation reaction can occur at higher temperatures with this catalyst, but the reactions are not very selective.

The reaction of ethanol with $\mathrm{Rh}_{2} \mathrm{O}_{3}-\mathrm{HT} / \mathrm{K}$ at $400^{\circ} \mathrm{C}$ gave ethylene as the only product. The rhodium catalyst was much less active than it was in the batch reactions discussed above.

\section{REFERENCES}

1. Mills, G.A. Catalysts for Fuels from Syngas, IEA Coal Research, London, 1988.

2. Forzatti, P.; Tronconi, E.; Pasquon, I. Catal. Rev.-Sci. Eng. 1991, 33, 109.

3. Naumann, A.W.; Behan, A.S. US Patent 4243553.

4. Sharma, R.K.; Olson, E.S. "Catalytic Hydrodesulfurization with Hydrotalcites," In Processing and Utilization of High-Sulfur Coals IV; Dugan, P.R.; Quigley, D.R.; Attia, Y.A., Eds.; Elsevier: Amsterdam, 1991; pp 377-384.

5. Fujimoto, K.; Oba, T. Appl. Catal. 1985, 13, 289. 
6. Tatsumi, T.; Muramatsu, A.; Tominaga, H.O., Appl. Catal. 1987, 34, 77.

7. Guerbet, M. C.R. Acad Sci. 1909, 49, 129.

8. Pratt, E.F.; Kubler, D.G. J. Amer. Chem. Soc. 1954, 76, 52.

9. Miller, R. E.; Bennett, G.E. US Patent 2762 847, 1953.

10. Dvornikoff, M.N.; Farrar, M.W. J. Org. Chem. 1957, 22, 540.

11. Carter, C.A. US Patent $2457866,1949$.

12. Farrer, M.W. US Patent $2971633,1961$.

13. Pregaglia, G.; Gregorio, G.; Conti, F. US Patent 3514 493, 1970; US Patent 3479412 , 1969.

14. Yates, J.E. US Patent 3917 722, 1975.

15. Burk, P.L.; Pruett, R.L.; Campo, K.S. J. Molecul. Catal. 1985, 33, 1.

16. Clark, R.T. US Patent 3972 952, 1976.

17. Ueda, W.; Kuwabara, T.; Ohshida, T.; Morikawa, Y. J. Chem. Soc. Chem. Commun. 1990, 1588.

18. Suzuki, E.; Ono, Y. Bull. Chem. Soc. Japan 1988, 61, 1008. 
J:BAYYTACa

- FORM EIA-459E

$(10 / 88)$

1. Program/Project Identification No. DE-FC21-93MC30097

4. Name and Address
U.S. DEPARTMENT OF ENERGY

FEDERAL ASSISTANCE MANAGEMENT SUMMARY REPORT

2. Program/Project Title

TASK 4.0 ADVANCED FUEL FORMS

Energy \& Environmental Research Center

University of North Dakota

PO Box 9018, Grand Forks, ND 58202-9018 $\quad$ (701) 777-5000
FORM APPROVED

OMB NO. 19000127

Page 1 of 2

3. Reporting Period

10-1-96 through 12-31-96

5. Program Start Dato

$01-12-93$

6. Completion Date

12-31-97

\begin{tabular}{|c|c|}
\hline $\begin{array}{c}\text { 7. FY } \\
96 / 97\end{array}$ & $\begin{array}{c}\text { 8. Months or Quarters } \\
\text { Quarters }\end{array}$ \\
\hline $\begin{array}{c}\text { 9. Cost } \\
\text { Status }\end{array}$ & $\begin{array}{c}\text { a. Dollars Expressed In } \\
\text { Thousands }\end{array}$ \\
\hline
\end{tabular}

10. Cost Chart

\begin{tabular}{|c|c|c|c|c|c|c|c|}
\hline \multirow{2}{*}{\multicolumn{2}{|c|}{$\begin{array}{l}\text { Fund } \\
\text { Source }\end{array}$}} & \multicolumn{4}{|c|}{ Quarter } & \multirow{2}{*}{$\begin{array}{c}\text { Cum. } \\
\text { to } \\
\text { Date }\end{array}$} & \multirow{2}{*}{$\begin{array}{l}\text { Tot. } \\
\text { Plan }\end{array}$} \\
\hline & & \multirow{2}{*}{$\frac{1 \text { st }}{0}$} & \multirow{2}{*}{$\frac{2 \text { nd }}{14}$} & \multirow{2}{*}{$\frac{3 \mathrm{rd}}{13}$} & \multirow{2}{*}{ 4th } & & \\
\hline DOE & $\mathbf{P}$ & & & & & 40 & 40 \\
\hline & A & 0 & 10 & 21 & 7 & 38 & \\
\hline & $\mathbf{P}$ & & & & & & \\
\hline & A & & & & & & \\
\hline & $\mathbf{P}$ & & & & & & \\
\hline & A & & & & & & \\
\hline & $\mathbf{P}$ & & & & & & \\
\hline & A & & & & & & \\
\hline Tot & & 0 & 14 & 13 & 13 & 40 & 40 \\
\hline Tot & & 0 & 10 & 21 & 7 & 38 & \\
\hline Varia & & 0 & 4 & (8) & 6 & 2 & \\
\hline
\end{tabular}

Total Planned Costs for Program/Project $\$ 40$

11. Major Milestone Status

4.9 Value-Added Products from Syngas c. Cumulative Accrued Costs

\begin{tabular}{|l|r|r|r|l|l|r|r|r|r|r|r|r|}
\hline Planned & & 0 & & & 14 & & & 27 & & & 40 \\
\hline Actual & & & 0 & & & 10 & & & 31 & & & 38 \\
\hline Variance & & 0 & & & 4 & & & -4 & & & 2 \\
\hline
\end{tabular}

\begin{tabular}{|l|l|l|l|l|l|l|l|l|l|l|l|l|}
\hline $\begin{array}{l}\text { b. Dollar } \\
\text { Scale }\end{array}$ & 2st & 2nd & \multicolumn{3}{|l|}{ 3rd } & 4th & \\
\cline { 2 - 9 } & JAN & FEB & MAR & APR & MAY & JUN & JUL & AUG & SEP & OCT & NOV & DEC \\
\cline { 2 - 7 } &
\end{tabular}

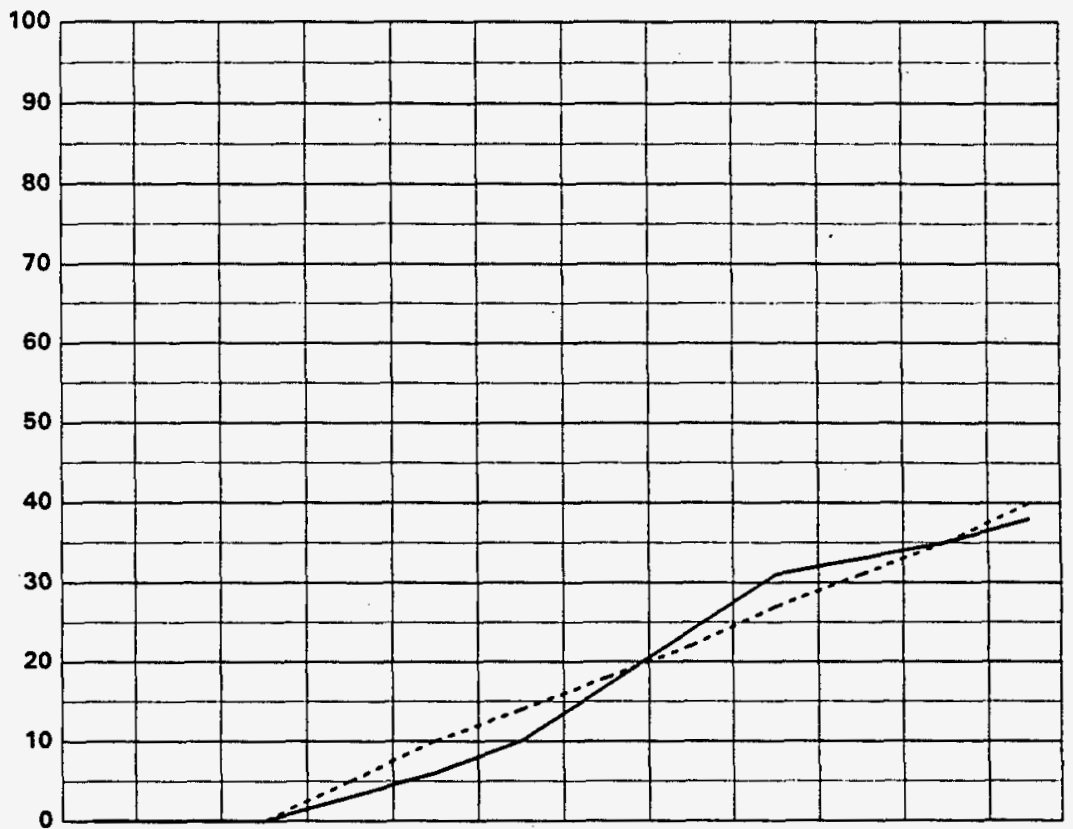

(1)

\section{Remarks}

13. Sigfature of Recipient and Dote 2 
r FORM EIA-459E $(10 / 80)$

\section{FEDERAL ASSISTANCEARTMENT OF ENERGY}

FEDERAL ASSISTANCE MANAGEMENT SUMMARY REPORT

FORM APPROVED

OMB NO. 19000127

Page 2 of 2

1. Program/Project Identification No. DE-FC21-93MC30097

4. Name and Address

Milestone

ID. No.

Subtask 4.9

a

b

c
2. Program/Project Title Task 4.0 ADVANCED FUEL FORMS

Energy \& Environmental Research Center

University of North Dakota

PO Box 9018, Grand Forks, ND 58202-9018

701) $777-5000$
Optimize composition of catalyst

Determine conditions for fixed bed flow-through reactions of syngas

Complete matrix of conditions for syngas batch reactions with 'MoTPHT catalyst

7.5000

3. Reporting Period $10 / 1 / 96$ through $12 / 31 / 96$

5. Program Start Date

$1 / 12 / 93$

6. Completion Date 12-31-97

Planned

Completion Date

Actual Completion Date Comments

Value-Added Products from Syngas

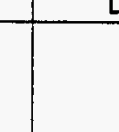

$9 / 96$
$12 / 96$

$12 / 96$

$9 / 30 / 96$

$12 / 96$

$12 / 96$ 


\section{M97002236}

|||||||||||||||||||||||||||||||||||||||||||||||||||||||||

Report Number (14) DOE/NC/30097-

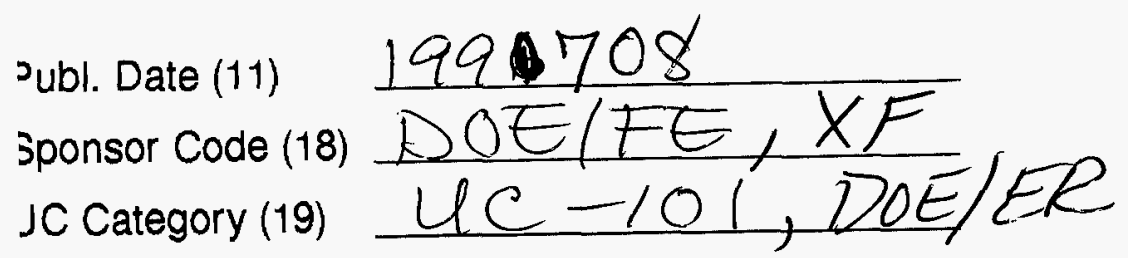

